\title{
Study on toxic metal levels in commercial marine organisms from Romanian market
}

\author{
Sonia AMARIEI*, Gheorghe GUTT, Mircea OROIAN and Alexandra BODNAR
}

\author{
Stefan cel Mare University of Suceava, Faculty of Food Engineering, 13, Universitatii Street, Suceava, \\ ROMANIA
}

\begin{abstract}
The goal of this study was to analyze the content of heavy metals in fish, shellfish, molluscs cephalopods on the Romanian market. We have analyzed heavy metals traces in sixteen marine organisms species. Analyses of heavy metal traces were done with mass spectrometer with inductively coupled plasmaICP-MS, Agilent Technologies 7500 Series. Among the elements identified it was analyzed the content of $\mathrm{Cd}$, $\mathrm{Hg}, \mathrm{Pb}$, metals with high toxicity to the human body, and the obtained values were interpreted in accordance with Commission Regulation (EC) No 1881/2006 concerning the maximum allowable quantity per kg wet product and Provisional Tolerated Weekly Intake (PTWI) established by the Joint Committee experts WHO / FAO. The risk assessment performed indicated that marine organisms were safe for the consumer except the four species that cadmium content may be exceeded for a regular or excessive consumption.
\end{abstract}

Keywords: heavy metals, risk assesment.

\section{Introduction}

Except for occupational diseases because of heavy metals $(\mathrm{Pb}, \mathrm{Cr}, \mathrm{Hg}, \mathrm{Mn}, \mathrm{Cd}, \mathrm{As}$,$) , man may$ be contaminated with heavy metals in unprofessional conditions, ie by ingesting contaminated food, water, and by air polluted by heavy metals [1],[2]. Toxic metals do not appear as free metal, but only in the form of combinations: salts, oxides, chelate complexes etc. Metal ions do not undergo any biochemical transformation in the body, they can change their valence and belonging to a group or different combinations and toxic effects can be analyzed in relation to the initial composition (eg pesticides, $\mathrm{Hg}, \mathrm{Sn}, \mathrm{Zn}$, and $\mathrm{Cu}$ ) [3] or by the nature of degradation products in soil, food and the body.

Metals for which we have sufficient data to prove their toxicity are: $\mathrm{Hg}, \mathrm{Pb}, \mathrm{Sb}, \mathrm{Cd}, \mathrm{Zn}, \mathrm{Cu}, \mathrm{Sn}$, $\mathrm{Ag}, \mathrm{Au}, \mathrm{Ni}, \mathrm{Cr}, \mathrm{V}$, and Al. Some of them are essential elements such as $\mathrm{Zn}, \mathrm{Cu}, \mathrm{Ni}, \mathrm{Cr}, \mathrm{Co}, \mathrm{V}$, which are toxic at higher doses than acceptable daily intake DAI. Practically all of chemical combinations are toxic metal above a certain dose specific to each element [4], [5].
The content of heavy metals in some fish species and other marine animals used in various diets, commercialized in Romanian supermarkets was analyzed in the paper. Fish is an extremely valuable food by its content [6] in high quality protein, fat rich in polyunsaturated fatty acids, vitamins (mainly $\mathrm{A}$ and $\mathrm{D}$ ) and minerals (iron, phosphorus, potassium, magnesium etc.).

Chemical pollution of water is the result of organic or inorganic discharge of compounds used in various industries (hydrocarbons, salts of heavy metals, acids and inorganic bases, organic synthetic substances) or in agriculture (phosphates, nitrates, amendments, pesticides) [7].

The average concentration of cadmium in seawater was evaluated at $0.3 \mu \mathrm{g} / \mathrm{L}$. In natural waters used as drinking water, cadmium is sometimes undetectable, sometimes found values did not exceed $0.06 \mu \mathrm{g} / \mathrm{L}$. Marine molluscs and crustaceans along with sardines and eels have the capacity to concentrate cadmium of 10000-100000 times from sea water. Maximum permissible limit of cadmium in fish under Commission Regulation (EC) $1881 / 2006$ is $0.050-0.10 \mathrm{mg} / \mathrm{kg}$ wet weight and in 
canned and semi-canned fish in oil and canned and semi-canned fish in tomato sauce or vinegar and salted, smoked or dried fish is $0.05 \mathrm{mg} / \mathrm{kg}$.

The main objective of the present research was the identification and quantitative analyses of toxic elements and determining the potential risk according with Provisional Tolerated Weekly Intake (PTWI).

\section{Experimental}

The determinations have been performed according to the Commission Regulation (EC) No 333/2007 of 28 March 2007 laying down methods of sampling and analysis for official control of levels of lead, cadmium, mercury, inorganic tin, 3-MCPD and benzo(a) pyrene in foodstuffs (Text with EEA relevance).

\subsection{Sampling and sample preparation}

Samples analyzed were purchased from Romanian market, totalling sixteen species of carnivorous and predators fish (pike, salmon, cod, sea wolf, shark, tuna, pangasius), zoofag micro carnivorous fish (mackerel, herring, sprat), omnivorous fish (carp, mackerel, chub), shellfish (shrimp), mollusks (clams), squid (cephalopods).

Organic matter in the sample is destroyed by carbonization and then, after burning in electric oven at $450-500^{\circ} \mathrm{C}$ the ash is dissolved in diluted hydrochloric acid.

$10 \mathrm{~g}$ of homogenized sample is weighed, with an accurate of $0.01 \mathrm{~g}$ and treated with $3 \mathrm{~mL}$ solution of magnesium nitrate, then evaporated and calcined at $450-500^{\circ} \mathrm{C}$ for 4 hours. The ash is treated with $5 \mathrm{~mL}$ hydrochloric acid and a drop of hydrogen peroxide, and then evaporated to dryness. Residue is treated again with $5 \mathrm{~mL}$ hydrochloric acid, diluted with $5 \mathrm{~mL}$ water and passed through a quantitative filter paper with medium porosity in a graduated flask of $10 \mathrm{~mL}$. In parallel a blank is prepared. All solutions were prepared with reagent grade chemicals and ultra-pure water $(18 \mathrm{M} \Omega \mathrm{cm})$; nitric acid and hydrochloric acid were ultrapure from Sigma Aldrich.

\subsection{Reagents}

- Magnesium nitrate, solution $10 \%$ purified of heavy metals by stirring with $0.005 \%$ dithizone in carbon tetrachloride or chloroform;
- Diluted hydrochloric acid in admixture with acetic acid: one volume of hydrochloric acid, d $=1.10-1.19$ is mixed with two volumes of water; $1 \mathrm{~mL}$ of glacial acetic acid is added to 100 $\mathrm{mL}$ solution prepared as above;

- Hydrogen peroxide solution $30 \%$.

\subsection{Apparatus}

The analysis of samples were done using atomic emission in plasma coupled with mass spectrometry technique with ICP-MS Agilent Technologies 7500 Series device with a detection limit of $10^{-12}$ [9].

\subsection{Data processing}

Principal Component Analysis was performed with the software Unscrambler X 10.1 (Camo, Norway) according to the moisture content, ash content and the concentration of various minerals $(\mathrm{Li}, \mathrm{B}, \mathrm{Mg}, \mathrm{Al}$, $\mathrm{K}, \mathrm{Ca}, \mathrm{Cr}, \mathrm{Mn}, \mathrm{Fe}, \mathrm{Co}, \mathrm{Ni}, \mathrm{Cu}, \mathrm{Zn}, \mathrm{Ga}, \mathrm{As}, \mathrm{Se}, \mathrm{Br}$, $\mathrm{Ag}, \mathrm{Cd}, \mathrm{Sn}, \mathrm{Pt}, \mathrm{Ce}, \mathrm{Au}, \mathrm{Hg}, \mathrm{Pb}, \mathrm{Bi}, \mathrm{U})$.

\subsection{Risk assessment}

The Estimated Daily Intake (EH s) was calculated for $\mathrm{Cd}$ and compared with tolerable Daily Intake (TD / S). The data is based on the assumption that body weight is $60 \mathrm{~kg}$ :

where:

$$
\mathrm{EDI}=(\mathrm{CxFDC}) / \mathrm{BW}
$$

C - the concentration of contaminant $(\mu \mathrm{g} / \mathrm{g})$, FDC stand for fish daily consumption $(\mathrm{g} / \mathrm{d})$ and

$\mathrm{BW}$ - the body weight $(\mathrm{kg})[3]$.

$$
P T W I=\frac{C \cdot W C I}{B W}
$$

where:

$$
\begin{aligned}
& \text { PTWI - provisional tolerable weekly intake, } \\
& \mathrm{mg} / \mathrm{kg} \text { bw }
\end{aligned}
$$

\section{Results and discussions}

\subsection{Metal analysis}

Most of elements of the Periodic Table were identified and quantitatively determined in the solutions of sixteen samples, as follows in Table $\mathbf{1}$.

Previously, moisture and ash were determined for all samples, according to Table 2 . 
Table 1. Concentration of elements in samples' solution (ppb)

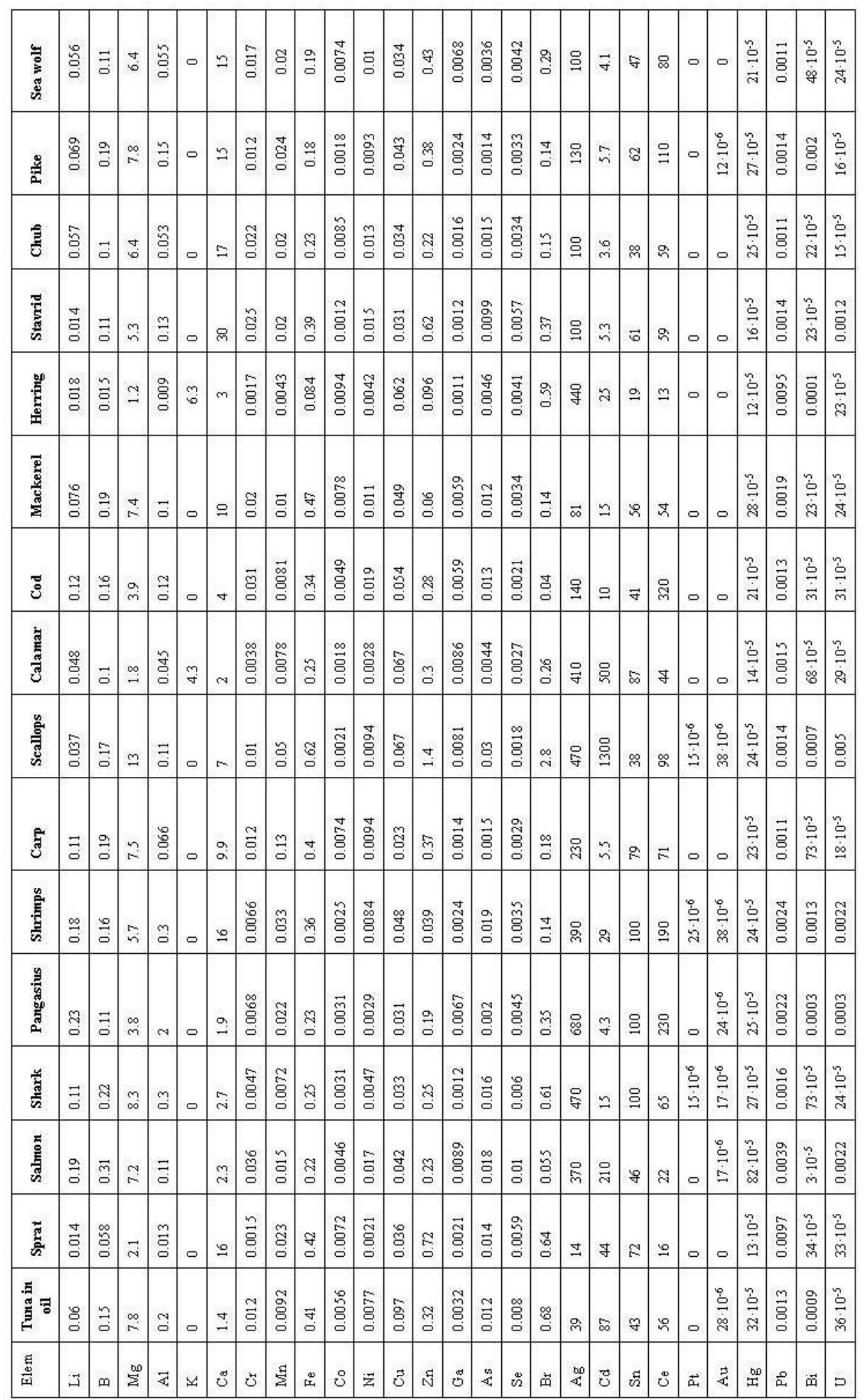


Concentration (C) of heavy metals in samples is expressed in $\mu \mathrm{g} / \mathrm{g}$ sample and calculated by the formula:

$$
\mathrm{C}=a \cdot \frac{V}{m},[\mu \mathrm{g} / \mathrm{g}]
$$

where:

a - measured concentration, in sample's solution $[\mathrm{ppb}]$;

$\mathrm{V}$ - volume of acid which was dissolved the sample, $[\mathrm{mL}]$;

$\mathrm{m}$ - mineralized weight sample, [g].

Table 2. Moisture and ash of samples

\begin{tabular}{|l|l|l|l|}
\hline Sample & $\begin{array}{l}\text { Weight } \\
(\mathrm{g})\end{array}$ & $\begin{array}{l}\text { Moisture } \\
(\%)\end{array}$ & Ash (\%) \\
\hline Tuna în oil & 5.074 & 62.96 & 0.53 \\
\hline $\begin{array}{l}\text { Sprat } \\
\text { smoked in } \\
\text { oil }\end{array}$ & 5.0151 & 58.86 & 0.82 \\
\hline Salmon & 5.0331 & 73.36 & 0.16 \\
\hline Shark & 5.0913 & 71.80 & 0.48 \\
\hline Pangasius & 5.0029 & 79.30 & 0.77 \\
\hline Shrimps & 5.0776 & 87.16 & 0.93 \\
\hline Carp & 5.1516 & 64.80 & 0.38 \\
\hline Scallops & 5.1124 & 59.64 & 0.52 \\
\hline Calmar & 5.1639 & 73.22 & 1.07 \\
\hline Cod & 5.0392 & 76.74 & 0.61 \\
\hline Mackerel & 5.0028 & 68.94 & 0.71 \\
\hline Herring & 5.0811 & 44.86 & 0.93 \\
\hline Stavrid & 5.0314 & 64.38 & 0.42 \\
\hline Chub & 5.1056 & 60.94 & 0.33 \\
\hline Pike & 5.0078 & 68.19 & 0.13 \\
\hline Sea wolf & 5.0705 & 58.55 & 0.36 \\
\hline
\end{tabular}

The values of $m$ are shown in Table 2 and of $a$ in Table 1. The volume of acid solution to dissolve the sample was $25 \mathrm{~mL}$. After analyzing the samples maximum permissible dose was exceeded for cadmium. Cd content, expressed in $\mathrm{mg} / \mathrm{kg}$ wet weight was exceeded in salmon case of 20.86 times, 6.35 times for scallops, 4.84 times for calamari, 2.14 times for tuna in oil, according with maximum limits for Cd in different fish species (EC 1881/2006), The maximum permissible dose of cadmium per $\mathrm{kg}$ of wet product was exceeded in 4 cases (Fig. 1).

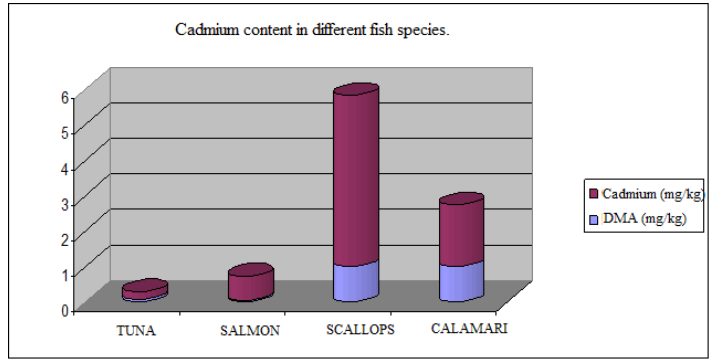

Fig.1. Samples that cadmium content exceeds maximum permissible dose.

Cadmium is more concentrated in marine mollusks, crustaceans, than in the fish as very similar to those recently found by E. Beccaloni, et al, [1].

Tin was found in only four cases (Fig.2), without exceeding the maximum permissible dose, being dependent on the concentration of tin in the water, its source being a result of water pollution due to the use of fungicides in agriculture.

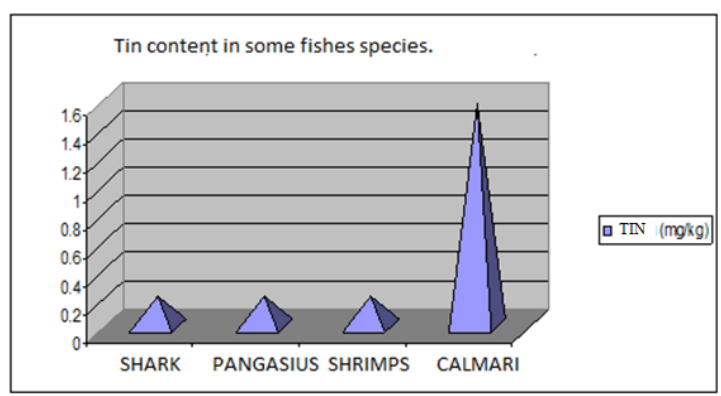

Fig.2 . Tin content in some marine organisms species

\subsection{Data processing}

Principal Component Analysis was carried out to evaluate the effect on the overall chemical composition of the variety of marine organisms (Fig. 3 and 4) and to determine the significant differences among fish species. Figures 3 and 4 present scores of samples in the reduced space and the influence of chemical composition in Principal Component Analysis. 


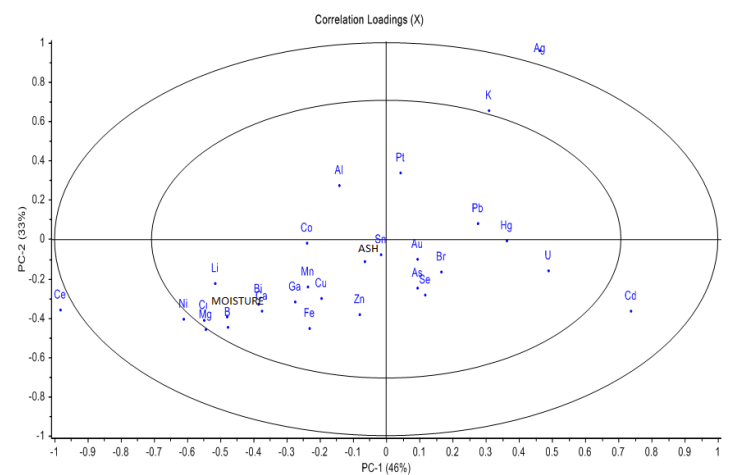

Fig.3. Principal Component Analysis of samples

Principal component 1 (PC1) explained $46 \%$ of variance, while component 2 (PC2) explains $33 \%$ of variation, the overall percentage of variation of the two main components being $79 \%$.

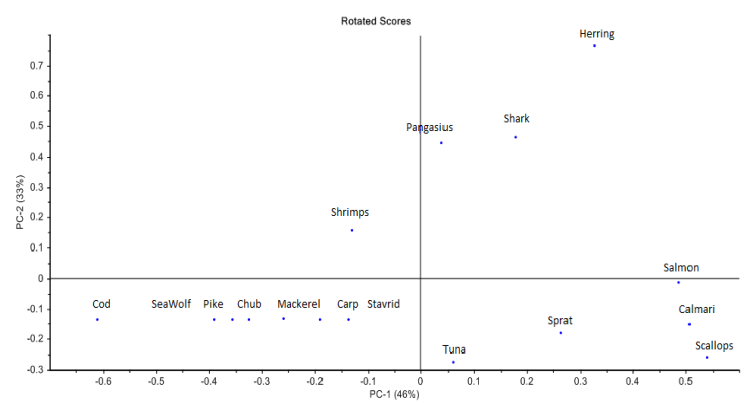

Fig.4. Influence of chemical composition and score of samples.

PC1 component distinguishes samples according to the content of $\mathrm{Ce}, \mathrm{Ni}, \mathrm{Cr}, \mathrm{Mg}, \mathrm{W}, \mathrm{Cd}$, while PC2 component distinguishes samples to the content of the $\mathrm{Ag}, \mathrm{K}$ and $\mathrm{Pt}$. Tin and gold concentrations near the origin of coordinates shows that these parameters are not useful in the total variation. Component $\mathrm{PC} 1$ distinguishes types of marine organisms in two categories: the first consists of cod, sea wolf, chub, pike, mackerel, carp, mackerel, tuna, sprat, salmon, calamari and mussels, and the second consisting of shrimp, pangasius, shark and mackerel.

According to Pearson correlations $(0.7<\mathrm{r}<1)$, the elements that are cross-correlation (dependent on each other) are: $\mathrm{Cr}-\mathrm{Ni}, \mathrm{Zn}-\mathrm{Br}, \mathrm{Zn}, \mathrm{Cd}, \mathrm{Ag}, \mathrm{Al}, \mathrm{Cd}$, $\mathrm{Br}, \mathrm{Cd}, \mathrm{U}, \mathrm{Pt}-\mathrm{Au}$.

\subsection{Risk assessment}

In the Commission Regulation (EC) No 1881/2006 of 19 December 2006 was setting maximum levels for certain contaminants in foodstuffs. The previous guideline for a maximum recommended Cd intake of $1 \mathrm{mg} / \mathrm{kg}$ body weight per day is thus shown to be too high to ensure that renal dysfunction does not occur as a result of dietary $\mathrm{Cd}$ intake.

Average adult intakes of cadmium were, with one exception, below the Provisional Tolerate Weekly Intake (PTWI) of $7 \mathrm{mg} / \mathrm{kg}$ bw [11].

Provisional Tolerate Weekly Intake (PTWI) is about $25 \mathrm{mg} / \mathrm{kg}$ bw in four countries providing data. At a consumption of $150 \mathrm{~g}$ product per day, 3 times a week, the content of $\mathrm{Cd}$ is overcome by 2.59 times in the case of the squid, shellfish 2.72 times in the case of 1.1 times in salmon.

\section{Conclusions}

Laboratory tests revealed that five of the samples had a higher content of tin determined in: carp, Pangasius, shark, shrimp, calamari, but without exceeding Provisional Tolerated Weekly Intake (PTWI) of 25 micrograms / kg bw.

Maximum permissible dose of cadmium was exceeded in four cases: tuna, salmon, scallops and calamari.

\section{References}

*E-mail address: gutt_sonia@yahoo.com

[1]. E. Beccaloni, F. Vanni, M. Beccaloni and M. Carere, Microchemical Journal 107, 190-195 (2013)

[2]. A.L.Hinwood, A.C.Callan, M.Ramalingam, M.Boyce, J.Heyworth and P.McCafferty, J.Ø.Odland, Environmental Research 126, 118 124 (2013)

[3]. Yared Beyene Yohannes, Yoshinori Ikenaka, Shouta M.M. Nakayama, Aksorn Saengtiencha, Kensuke Watanabe and Mayumi Ishizuka, Chemosphere 91, 857-863 (2013) 
[4]. G.N. Lion and J.O. Olowoyo, South African Journal of Botany 88, 178-182 (2013)

[5]. Muhammad Shahbaz, Muhammad Zaffar Hashmi, Riffat Naseem Malik and Azra Yasmin Chemosphere 93, 274-282 (2013)

[6]. A. Chahid, M. Hilali, A. Benlhachimi and T. Bouzid, Food Chemistry 147, 357-360 (2014)

[7]. Bin Fang, Xueqin Zhu, Food Control 39, 62-67 (2014)

[8]. J.A. Rodríguez Martín, J.J. Ramos-Miras, R. Boluda and C. Gil, Geoderma 200-201, 180188 (2013)
[9]. Xin Li, Zhaowei Zhang, Peiwu Li, Qi Zhang, Wen Zhang and Xiaoxia Ding, Food Research International 53, 649-658 (2013)

[10]. H. Pourgheysari, M. Moazeni, A. Ebrahimi, International Journal of Environmental Health Engineering, 1(1), 41-45 (2012)

[11]. $* * *$ European Commission. Report from task 3.2.11: Assessment of the dietary exposure to arsenic, cadmium, lead and mercury of the population of the EU Member States. European Commission. Directorate General Health and Consumer Protection.

Submitted: May $6^{\text {th }} 2014$ Accepted in revised form: October $29^{\text {th }} 2014$ 